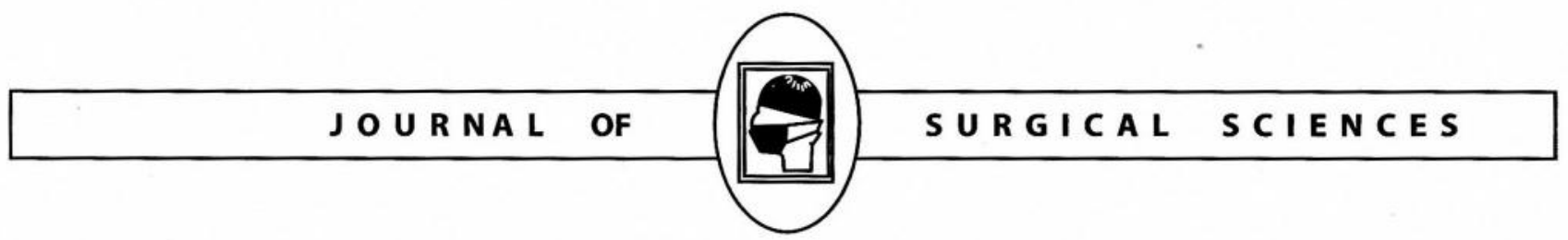

Editorial

\title{
IDIOPATHIC GRANULOMATOUS MASTITIS: DILEMMAS IN DIAGNOSIS AND TREATMENT
}

\author{
Dr. AZM Mostaque Hossain \\ Professor of Surgery, Dhaka Medical College, Dhaka
}

Idiopathic Granulomatous Mastitis (IGLM) is a chronic non-specific inflammatory lesion of the breast. It is characterized by the presence of epitheloid and multinucleated giant cell granulomas limited to the mammary lobules with micro-abscesses in the absence of obvious etiology.

IGLM remains a diagnosis of exclusion and the clinical findings are non-specific. A recent history of pregnancy, lactation, and use of oral contraceptive are factors that play an important role in the etiology of IGLM. High levels of serum prolactin as well as distention of the acini and ducts may result in a rupture of these structures, inducing a granulomatous response. Age at presentation is generally between 20 and 50 years so, IGLM can be considered a disease of women at a reproductive age.

The most common clinical sign is a unilateral painful breast mass that easily mimics a malignant mass. Skin lesions and enlarged axillary lymph nodes are other suspicious signs of malignancy. Ultrasound and mammography identify an irregular and ill defined mass in the majority of patients and can lead to a misdiagnosis of malignant changes. However, ultrasound images of multiple abscess collections in addition to structural changes and a breast mass may indicate the presence of an inflammatory granulomatous process. Histopathological evaluation plays a very important role in differentiating these lesions from other granulomatous conditions, inflammatory changes, and carcinoma. Diagnosis of IGLM is established through the use of FNAC in the majority of patients, while core and incisional biopsy is required in some inconclusive results on FNAC. The histopathological features of IGLM are granuloma, composed of epitheloid histiocytes with giant cells within and around the lobules. The absence of caseating necrosis and predominant neutrophilic background are important clues favoring a diagnosis of IGLM.

There is still no accepted management strategy for IGLM. Oral corticosteroids and surgery have both been used as treatment options. Limited excision alone has little benefit as there is a strong tendency of recur- rence. Excision of breast tissue ensuring negative margins for inflammatory granulamatous tissue may be curable, but may have unfavorable cosmetic results. Initial medical treatment by oral steroids followed by surgical excision of the remaining lesions can be carried out 2 weeks later.

In conclusion, IGLM is a chronic inflammatory breast disease found in young women of reproductive age. When faced with this clinical picture, the most important step of diagnosis is to remember the possibility of IGLM as a cause. Awareness of IGLM in young women with painful breast mass leads to a more accurate diagnosis by medical practitioners.

\section{References:}

1. Tuli R, O'Hara BJ, Hines J, Rosenberg AL. Idiopathic granulomatous mastitis masquerading as carcinoma of the breast: a case report and review of the literature. Int Semin Surg Oncol. 2007;4:21.

2. Erozgen F, Ersoy YE, Akaydin M, Memmi N, Celik AS, Celebi F, et al. Corticosteroid treatment and timing of surgery in idiopathic granulomatous mastitis confusing with breast carcinoma. Breast Cancer Res Treat. 2010;123:447-452.

3. Asoglu O, Ozmen V, Karanlik H, Tunaci M, Cabioglu $N$, Igci $A$, et al. Feasibility of surgical management in patients with granulomatous mastitis. Breast J. 2005;11:108-114.

4. Bani-Hani KE, Yaghan RJ, Matalka II, Shatnawi NJ. Idiopathic granulomatous mastitis: time to avoid unnecessary mastectomies. Breast J. 2004;10:318-322.

5. Lee JH, Oh KK, Kim EK, Kwack KS, Jung WH, Lee HK. Radiologic and clinical features of idiopathic granulomatous lobular mastitis mimicking advanced breast cancer. Yonsei Med J. 2006;47:78-84.

6. Gupta RK. Fine needle aspiration cytology of granulomatous mastitis: a study of 18 cases. Acta Cytol.2010;54:138-141. 